\title{
II Научно-практический семинар по вопросам применения комплектующих, ЭКБ и материалов в РЭА ВВСТ
}

\author{
Ю. Ковалевский
}

\begin{abstract}
В соответствии с решением Министерства промышленности и торговли и Министерства обороны Российской Федерации 28 марта 2019 года состоялся II Научно-практический семинар «Порядок применения комплектующих изделий, электронной компонентной базы и материалов в обеспечение разработки, модернизации и производства РЭА ВВСТ".
\end{abstract}

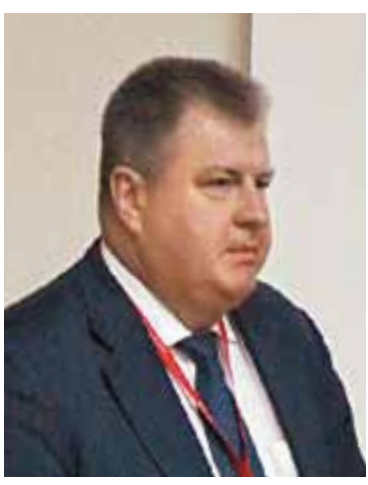

В качестве организаторов мероприятия выступили Минпромторг России ФГУП «МНИИРИП», Минобороны России, ФГБУ «46 ЦНИИ» Минобороны России АНО "Электронсертифика» и Группа компаний ТД «Альфа-Комплект» ЭКБ. Семинар проводили заведующий базовой кафедрой менеджмента в сфере систем вооруПавел Павлович Куцько жений МИРЭА С.И.Боков и первый заместитель директора ФГУП "МНИИРИП" В.В.Алексеев.

В начале мероприятия со вступительным словом выступил директор ФГУП "МНИИРИП" П.П. Куцько, который заострил внимание на вопросах доступности информации об отечественной ЭКБ для разработчиков РЭА, указав на то, что в этом вопросе ФГУП «МНИИРИП» берет на себя роль единого окна.

Далее участников семинара поприветствовали С. И. Боков и В. В. Алексеев, отметив, что данное меро-

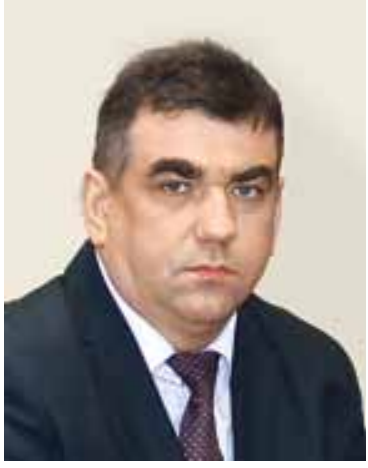

Виктор Валентинович Алексеев приятие призвано в том числе способствовать взаимодействию между Минпромторгом и Минобороны России в вопросах обеспечения отечественными комплектующими, ЭКБ и материалами современных изделий ВВСТ, и призвав обозначать имеющиеся проблемы и вносить свои предложения.

Затем прозвучал ряд докладов по теме семинара, представленных сотрудниками

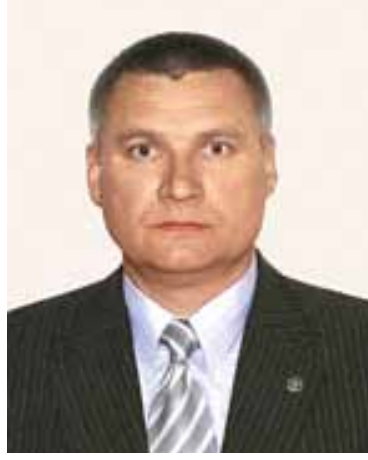

Сергей Иванович Боков
ФГБУ «46 ЦНИИ» Минобороны России, ФГУП «МНИИРИП», АО «РНИИ "Электронстандарт», ГК "Росатом» и других структур и организаций, а также отраслевых компаний.

В докладах рассматривались вопросы планирования разработки и создания ЭКБ и материалов в интересах Минобороны России и госкорпораций, каталогизации, обеспечения технологической независимости, установления соответствия технических параметров и эксплуатационных характеристик ЭКБ заданным требованиям, деятельности испытательных лабораторий, добровольной сертификации, работы военных представительств и др. Также была поднята тема возможности применения в изделиях специального назначения ЭКБ

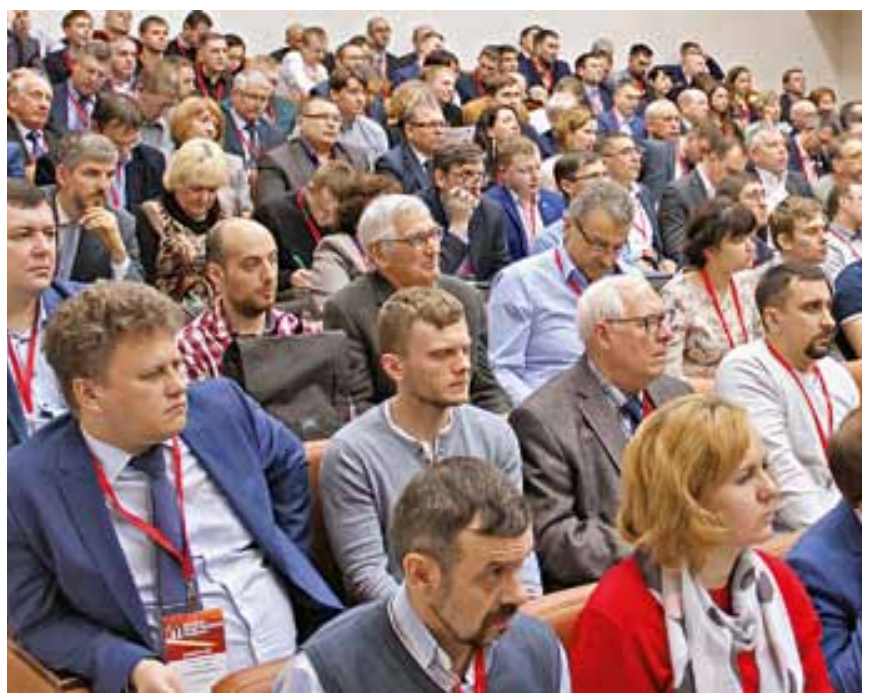


с приемкой ОТК с целью замены импортных электронных компонентов.

Среди наиболее распространенных проблем, связанных с порядком применения комплектующих и ЭКБ в РЭА ВВСТ, представителями органов, отвечающихза выполнение соответствующих процедур, были обозначены ошибки при подаче предприятиями заявок и неполнота предоставляемых сведений.

Кроме того, в рамках мероприятия говорилось о проблемах подготовки кадров для структур, выполняющих исследования и оценку комплектующих и ЭКБ для определения возможности их применения при разработке, модернизации и производстве образцов ВВСТ. В частности, С. И. Боков в своем докладе указал на особенности данной подготовки и рассказал о деятельности недавно созданной в МИРЭА базовой кафедры, направленной на решение этой задачи.

В заключение мероприятия П.П.куцько представил присутствующим возможности созданной ФГУП «МНИИРИП» торгово-информационной площадКИ "ЭКБ МАРКЕТ», а также рассказал об интегрированном центре испытаний ЭКБ и РЭА и другой деятельности института по информационному обеспечению электронной и радиоэлектронной отрасли

\section{Комментирует генеральный директор Группы компаний Тд "Альфа-Комплект" ЭКБ}

\section{А. И. Роман}

Состоявшийся в марте этого года II Научно-практический семинар, посвященный порядку применения комплектующих изделий, электронной компонентной базы и материалов в обеспечение разработки, модернизации и производства РЭА ВВСТ, продолжил зародившуюся в 2017 году традицию по проведению мероприятий такого формата, помогающих предприятиям электронной и радиоэлектронной отрасли эффективно взаимодействовать с государственными контролирующими организациями в том числе по вопросам создания и применения современной отечественной ЭКБ для обеспечения импортонезависимости и достижения высоких технических характеристик, качества и надежности образцов ВВСТ.

Ценность таких мероприятий исключительна: они позволяют в непосредственном общении между представителями предприятий, госкорпораций, федеральных органов государственной власти и органов военного управления, а также квалифицированных поставщиков и других заинтересованных сторон поднимать практические вопросы, получать ответы из первых уст и находить решения существующих проблем.

Мы очень рады, что наша Группа компаний способствует этой деятельности, уже второй раз принимая непосредственное участие в организации дан ${ }^{-}$ ных семинаров.

Это мероприятие помогает доносить свою позицию до широкого круга лиц, обосновывать свои предложения перед лицом ответственных организаций. Группа компаний Тд "Альфа-Комплект» ЭКБ на прошедшем семинаре воспользовалась этой



возможностью. Мы обозначили необходимость возвращения закрепления военных представительств за квалифицированными поставщиками ЭКБ с целью контроля их деятельности, в чем мы абсолютно уверены, как в эффективном инструменте борьбы с недобросовестными поставщиками и контрафактной продукцией.

Я хотела бы выразить надежду на то, что традиция проведения данных семинаров будет продолжена, и призвать всех, кто задействован в процессах создания современной российской радиоэлектронной аппаратуры для образцов вооружения и специальной техники и кому небезразлично качество поставляемой продукции для этих критических изделий, принимать активное участие в таких мероприятиях. 


\section{甸ИHTECPAA}

\section{ИМС КАТЕГОРИИ КАЧЕСТВА «ВП»}

ЧЕТЫРЕХКАНАЛЬНОГО СУПЕРВИЗОРА ПИТАНИЯ 5322СХ035

Окончена ОКР «Визирь-1», в рамках которой разработана микросхема категории качества «ВП» 5322СХ035 четырехканального супервизора питания с контролем фиксированных напряжений питания 5,0 и 3,3 B и с контролем двух настраиваемых уровней напряжений от двух независимых источников питания с формированием сигнала "сброс». Микросхема предназначена для применения в РЭА специального назначения.

Микросхема изготавливается в малогабаритном металлокерамическом CLCC-корпусе 5119.16-А и функционирует при температуре от -60 до $+125^{\circ} \mathrm{C}$.

Функциональные аналоги микросхемы - микросхемы MAX6709GUB, MAX6709HUB компании Maxim Integrated. Технические условия - АЕНВ.431350.475-02 ТУ.

Таблица 1. Основные параметры и функциональные особенности микросхемы

\begin{tabular}{|l|c|}
\hline \multicolumn{1}{|c|}{ Наименование параметра } & Норма параметра \\
\hline Напряжение питания, B & $2,0+5,5$ \\
\hline $\begin{array}{l}\text { Пороговое напряжение на входе IN1 формирования } \\
\text { сигнала «сброс», Uтн1, B }\end{array}$ & $4,5+4,75$ или $4,25+4,5$ \\
\hline $\begin{array}{l}\text { Пороговое напряжение на входе IN2 формирования } \\
\text { сигнала жсброс», Uтн2, B }\end{array}$ & $3,0+3,15$ или $2,85+3,0$ \\
\hline $\begin{array}{l}\text { Настраиваемое пороговое напряжение формирования } \\
\text { сигнала ошибки, Uтна, B }\end{array}$ & $0,984+1,016$ \\
\hline Длительность сигнала сброса, мс & $140+280$ \\
\hline
\end{tabular}

\section{Основные фрункции микросхемы}

Контролируемые напряжения питания фиксированных каналов составляют 3,3 и 5,0 В, допуск отклонения контролируемого уровня напряжения от номинального 5 или 10\%. Два настраиваемых канала для возможности контроля напряжения питания двух независимых источников питания. Встроенная функция «сброс от внешней кнопки».

Микросхема содержит следующие основные блоки: источник опорного напряжения, блок резистивных делителей, блок компараторов, схему формирования сигнала «сброс», коммутатор, схему управления выходом.

Каждый канал микросхемы (по входам IN1, IN2, IN3, IN4) имеет свой независимый компаратор. Фиксированные каналы IN1, IN2 контроля напряжений питания 5,0 и 3,3 В имеют встроенные резистивные делители, напряжения выходов которых сравниваются с опорным напряжением. К двум настраиваемым каналам предполагается подключение внешних резистивных делителей, рассчитанных для контроля источников питания с разными напряжениями.

Микросхемы обладают следующими функциональными возможностями:

- формирование сигналов «сброс» $\overline{R E S E T}$ и RESET при контроле уровня напряжения питания 5,0 В на входе IN1 и при контроле уровня напряжения 3,3 B на входе IN2;

- формирование сигналов «сброс» $\overline{R E S E T}$ и RESET от внешней кнопки по входу $\overline{\mathrm{MR}}$ (функция ручного сброса);

- формирование сигналов ошибки по выходам $\overline{\mathrm{OUT} 1} \div \overline{\mathrm{OUT} 4}$ при контроле уровней напряжений источников питания на входах IN1 $\div$ IN4.

Микросхема имеет три основные функции. Первая функция - контроль уровней напряжения источников питания 5,0 и 3,3 В по фиксированным каналам IN1, IN2. Внутренний источник опорного напряжения и 


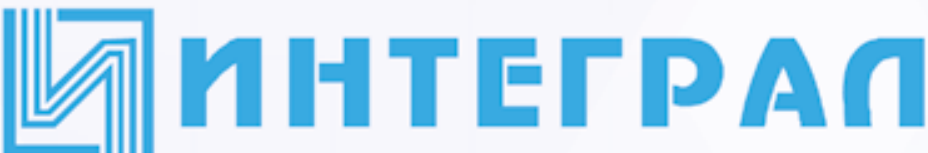

Рис. 1. Условное графическое обозначение

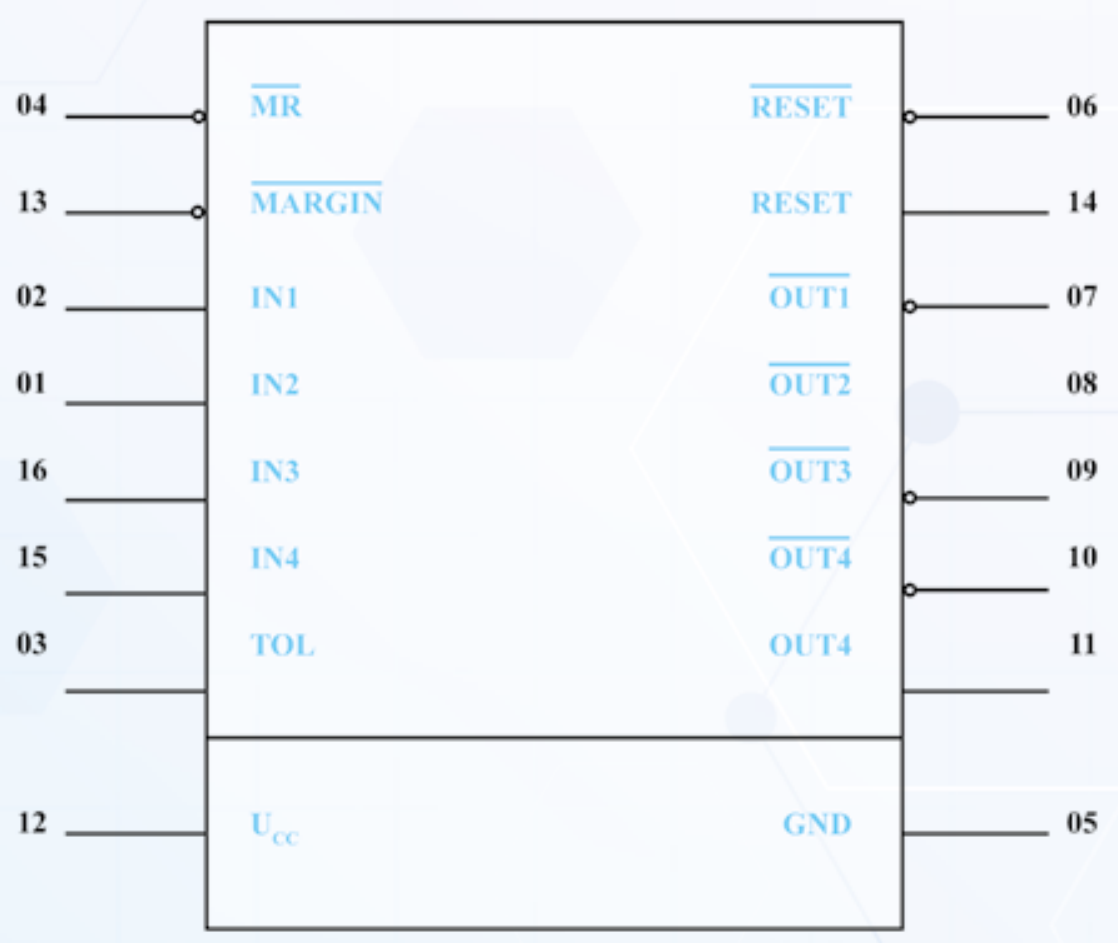

аналоговый компаратор анализируют напряжение источников на входах IN1, IN2. В случае возникновения сбойной ситуации, когда уровень напряжения питания на входе IN1 или IN2 опускается ниже уровня порогового напряжения $\bigcup_{\text {тн1 }}$ или $\bigcup_{\text {тн2, }}$ вырабатывается внутренний сигнал ошибки питания, переводящий сигналы «сброс» на выводах RESET и RESET в активное состояние. Выводы RESET и RESET будут оставаться в активном состоянии до тех пор, пока уровни напряжения источников питания остаются ниже порогового напряжения сброса ( $\bigcup_{T H 1}$ или $\left.\bigcup_{T H 2}\right)$. После возвращения уровня напряжения источника на входе IN1 или IN2 в устойчивое состояние сигналы «сброс» остаются активными не менее 140 мс, позволяя источнику питания и процессору стабилизироваться.

Вторая функция - «сброс от внешней кнопки». Микросхема имеет вход ручного сброса $\overline{\mathrm{MR}}$ от внешней кнопки. При подаче на вход $\overline{\mathrm{MR}}$ импульса активного низкого уровня формируются сигналы "сброс" на выводах RESET и RESET. Сигналы остаются в активном состоянии не менее 140 мс после того, как $\overline{\mathrm{MR}}$ переключится обратно из низкого уровня на высокий. Вход $\overline{\mathrm{MR}}$ имеет встроенный подтягивающий к питанию резистор порядка 20 кОм.

Третья функция - мониторинг состояния уровней напряжения внешних источников питания. Микросхема имеет два аналоговых входа (настраиваемых канала) IN3, IN4, которые соединены с входами соответствующих компараторов, на вторые входы которых подается опорное напряжение, вырабатываемое внутренним источником опорного напряжения. Настраиваемые каналы позволяют пользователю контролировать два внешних источника питания с разными напряжениями. Для задания контролируемого уровня напряжения внешних источников питания используются внешние резистивные делители напряжения, подключаемые к входам IN3 и IN4. При обнаружении падения уровня напряжения на определенном настраиваемом канале ниже порогового уровня напряжения UтнА микросхема формирует импульс на соответствующем выходе OUT активного низкого уровня (для входа IN4 дополнительно формируется еще и прямой сигнал активного высокого уровня на выходе ОUT4).

Bход TOL определяет допуск отклонения контролируемого уровня напряжения от номинального для фиксированных каналов IN1, IN2:

5\% - при подключении входа TOL к общему выводу GND;

$10 \%$ - при подключении входа TOL к выводу Uсc. 
Микросхема имеет вход $\overline{\text { MARGIN }}$ блокировки выходов. При подаче на вход $\overline{\text { MARGIN } и м п у л ь с а ~ а к т и в н о г о ~}$ низкого уровня все выходы микросхемы переводятся в неактивное состояние, что позволяет блокировать сигналы сброса при настройке системы. Вход MARGIN имеет встроенный подтягивающий к питанию резистор порядка 20 кОм.

Выходы микросхемы $\overline{\mathrm{RESET}}$ и $\overline{\mathrm{OUT} 1} \div \overline{\mathrm{OUT} 4}$ имеют слабую порядка 10 мкA подтяжку к питанию и схемотехнически выполнены таким образом, что при их подключении через внешний резистор к источнику с напряжением питания, большим Uсc микросхемы, ток утечки с этого источника на Uсc отсутствует.

Рис. 2. Временная диаграмма работы микросхемы

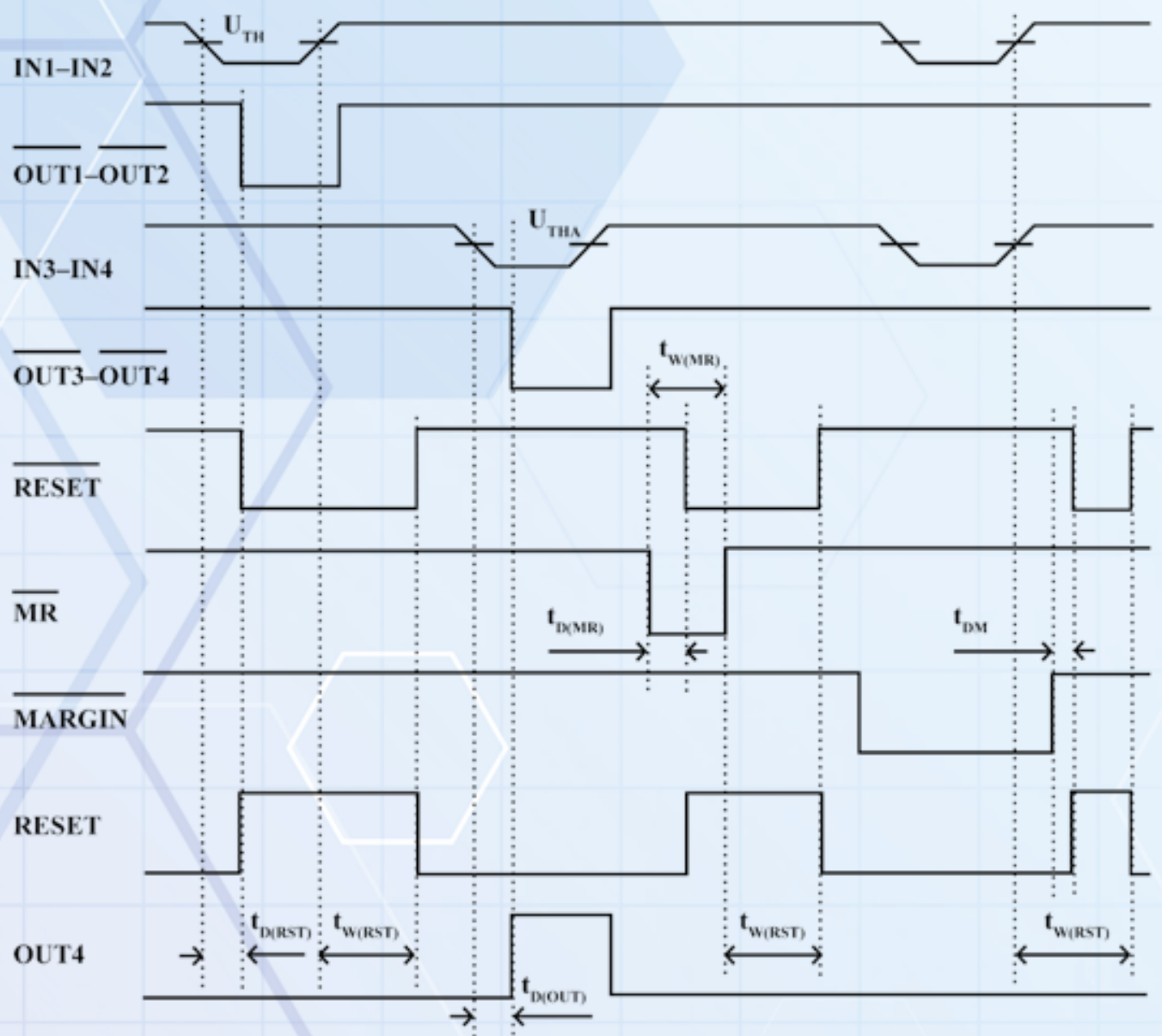

Микросхема 5322СХ035 имеет стойкость к воздействию специальных факторов: 7.И, 7.С и 7.К по




фическим отказам и тиристорному эффекту. В январе 2019 года подано предложение для включения микросхемы 5322CX035 в перечень ЭКБ 02. Возможна передача образцов микросхемы 5322СХ035 заинтересованным в ее опробовании предприятиям для проведения тестирования.

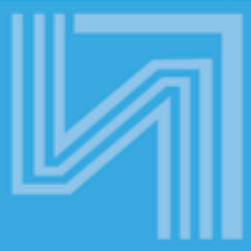

\section{ОАО «ИНТЕГРАЛ» -}

управляющая компания холдинга «ИНТЕГРАЛ»

Республика Беларусь E-mail: ATitov@integral.by

тел./факс: (+375-17) 3987203

тел.: $(+375-17) 2989743$ www.integral.by 
17-19

СЕНТЯБРЯ 2019

САНКТ-ПЕТЕРБУРГ КВЦ “ЭКСпОФОРУМ»

productronica

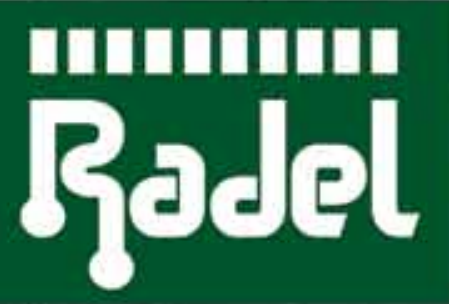

ХІХ МЕЖДУНАРОДНАЯ ВЫСТАВКА РАДИОЭЛЕКТРОНИКА
\& ПРИБОРОСТРОЕНИЕ

i. ЭЛЕКТРОННЫЕ КОМПОНЕНТЫ И КОМПЛЕКТУЮЩИЕ

- ПЕЧАТНЫЕ ПЛАТЫ И ДРУГИЕ НОСИТЕЛИ СХЕМ

- СВЕТОДИОДНЫЕ ТЕХНОЛОГИИ

i. РАЗРАБОТКА И ПРОИЗВОДСТВО ЭЛЕКТРОННЫХ УСТРОЙСТВ

- РОБОТОТЕХНИКА

- КОНСТРУКТИВЫ

- МАТЕРИАЛЫ

- ТЕХНОЛОГИИ

- ПРОМЫШЛЕННОЕ ОБОРУДОВАНИЕ И ИНСТРУМЕНТЫ

- КОНТРОЛЬНО-ИЗМЕРИТЕЛЬНЫЕ ПРИБОРЫ И ЛАБОРАТОРНОЕ ОБОРУДОВАНИЕ

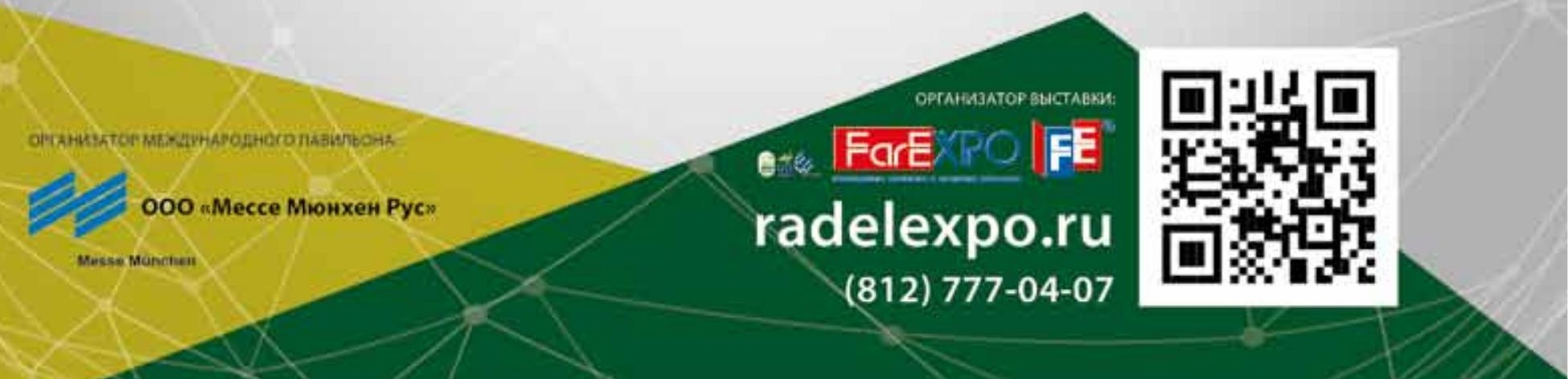

